\title{
Community Sport Social Benefits: A Basis for Continuous Improvement
}

\author{
By Carl S. Bozman* \\ Vivek H. Patil ${ }^{\dagger}$ \\ Lada V. Kurpist \\ Kevin Lehman ${ }^{+}$
}

\begin{abstract}
Community sport events, like any other sports endeavor, must be concerned with continuous improvement in order to remain or become competitive over time. In this study, we document a survey method that links the social benefits community sport attendees sought to levels of satisfaction and behavioral intentions. Using a combination of techniques such as OLS regression and word clouds for analyzing quantitative and qualitative data from our survey, our findings suggest that knowledge of the social benefits desired by a specific sport subculture may have several practical uses. For example, an awareness of desired social benefits may allow community sport managers to design and develop events with higher and more consistent levels of attendee satisfaction as well as obtain, or maintain, support from community residents and leaders. High levels of attendee satisfaction are found to be significantly related to the perceived social benefits of a community sport event as well as to the perception of the importance of the sport event to the community and individual intentions to support the event in the future.
\end{abstract}

\section{Introduction}

Community sport encompasses a broad range of physical activities that are organized by local sport groups and includes competitive as well as recreational sport (Pederson, Parks \& Quarterman, 2011). The process of continuous improvement is an important issue faced by every community sport management practitioner. Community sport is no different than professional sport in this regard. Community sport participants and spectators prefer superior products and will substitute other forms of recreation and entertainment when they believe there are better alternatives available. Local business and public support for a community sport will also depend on an event's relative perceived value. People who are neither sport participants nor spectators may be of greater consequence to a community sport because unlike a professional sport event, a community sport often relies on volunteers rather than paid staff and subsidies from the local community rather than admission fees.

\footnotetext{
* Professor, Gonzaga University, USA.

${ }^{\dagger}$ Professor, Gonzaga University, USA.

* Associate Professor, Gonzaga University, USA.

+ Gonzaga University, USA.
} 
Support for community sport can range from donations of time and money to the use of space and equipment. Why should individuals commit these limited resources to an event that might not otherwise be viable? The most common argument is beneficial economic impact. Community sport proponents often rely on economic input-output analysis to make a persuasive case for economic benefits. Economic input-output analysis, however, is not appropriate in circumstances where there is little infrastructure or associated employee expense (Rueda-Cantuche \& Ramirez-Hurtado, 2007). Many community sport events exhibit both the former characteristics. Even more importantly, most community sport participants and spectators are comprised mainly of people from within the local area. The expenditures of these attendees are, as a consequence, primarily substitutes from one form of local recreation or entertainment to another and inappropriate to include as a component of sport related economic benefit.

How then can community sport advocates enlist the assistance of individuals within a community when event organizers are unable to make a compelling case based on economic benefits? Another way to do so would be to demonstrate that local sport participants and spectators are (or will be) very satisfied with the event and consequently view the sport as an important means to help the community remain (or become) more socially connected (Hoye, Nicholson \& Brown, 2015). Creating a legacy of this type may be much more valuable to a community than any relatively short term economic benefits (c.f. Preuss, 2007). For example, individuals within a community might value a sport activity as a means to develop and/or maintain personal relationships. A community sport event can help individuals support family and friends, experience a feeling of camaraderie, and participate in a festive community building atmosphere (Kurpis, Bozman \& Kahle, 2010). Arguments for community support, based on the social benefits associated with a sporting event, have been espoused by several sport marketing and sport management researchers (Chalip, 2006; Chalip \& McGuirty, 2004; Schulenkorf, 2009).

Very little research, however, describes how the social benefits that may be associated with a community sport event are related to attendee community development expectations and satisfaction. A study by Xing, Chalip and Green (2014) provides a notable exception. The former authors found that the social benefits sought by women involved in a flag football tournament resulted in a positive sense of community. Previous studies have also linked a heightened sense of community to attendee satisfaction (Costa, Chalip, Green \& Simes, 2006; Chalip, Lin, Green \& Dixon, 2013). Despite the call to use social benefits in lieu of, or in addition to, economic benefits as a justification for supporting sport events, advocates have not demonstrated how the social benefits sought by sport participants and spectators increase attendee satisfaction and corresponding levels of community support.

In this paper, we map the social benefits sought by attendees and link those perceptions with community sport event satisfaction and support. Our methodology provides a benchmarking framework for community sport practitioners who may wish to use social benefits as a means for enlisting 
community support or as a mechanism for improving community sport events. We employ and test the approach using data from a relatively large community sport event affiliated with a local nonprofit organization. This study illustrates the efforts of one community sport organization to assess and enhance the overall experience of people who attend an annual three day sport event. The relationships between social benefits, attendee satisfaction, and behavioral intentions are discussed after presenting some background information on the event and the community in which the event is held. The study's survey methodology and data are summarized in a subsequent section. Results of this inquiry are presented immediately thereafter, in conjunction with some concluding remarks and suggestions for future research.

\section{Background}

Hoopfest has become an annual summer ritual in Spokane, Washington. The community sport event is held during the last weekend in June. Begun in 1993, Hoopfest has grown into the largest 3-on-3 basketball tournament in the world. It attracted over 27,000 basketball players, 200,000 spectators, and 3,000 volunteers in 2013. The tournament is organized by a local nonprofit corporation with just a few full time employees, utilizes more than four hundred and fifty basketball courts laid out on public streets and parking lots in the downtown core, and draws a significant proportion of its participants and spectators from within the local area. Members of a winning team, in a 16 team double elimination bracket, each receive a championship $t$-shirt and bragging rights until the following year.

The success of this community sports event becomes even more apparent when the size of the local community is considered. According the United States Census of Population, the county in which Hoopfest takes place has a population under 500,000 residents and is the largest metropolitan area between Seattle, Washington and Minneapolis/St. Paul, Minnesota (U.S. Census, 2010). The community has a relatively strong mix of businesses in the wholesale, retail, finance, construction and manufacturing industries as well as in health care, education and government services. Spokane serves as the major in-shopping and service center for a large and predominantly rural geographic region.

Why does the Spokane community exhibit such tremendous support for Hoopfest? Although there are certainly economic benefits which accrue to the community from those who travel to Spokane to participate, these benefits alone do not appear sufficient to justify closing the city core for three days. The event must be perceived to provide some other benefit, or benefits, that contribute to individual as well as community welfare. Community sport events like Hoopfest are thought by many to enhance the long term health of community members as well as socialize community members with desirable community values, especially for disadvantaged youth and marginalized adults (Lawson, 2005; Umberson, Crosnoe \& Reczek, 2010). Chalip (2006) points 
out that such events offer much more than economic value and that these social benefits include energy, excitement, and communitas. Social affiliation needs are needs that can be fulfilled through sport event participation and hosting and which may also strengthen community ties and contribute to community identity. Additional research also suggests that community-based sport programs and events may increase interaction between diverse social groups within a community, create a common social identity, and establish social capital within and among groups (Ingham \& McDonald, 2003; Schulenkorf, 2009; Verweel \& Anthonissen, 2006).

Participants, volunteers, and spectators compete in, facilitate, or attend an event because they perceive it as a means of achieving these and other socially based motives. Their satisfaction with a sport event will be commensurate with the degree that their expectations are met or exceeded. To the extent participants, volunteers, and spectators are satisfied with a sport event, they are more likely to be event advocates and brand loyal over a longer period than those who are not satisfied. Community sport events which satisfy these constituent groups should therefore grow more rapidly by retaining a higher proportion of former attendees than would otherwise be the case. Events that meet or exceed these expectations will also find it easier and less expensive to recruit new attendees because of positive word of mouth (c.f. Keller, 2009).

The List of Values (LOV) methodology (Kahle, 1983) was used to distinguish between the types of values Hoopfest fulfils for attendees. This LOV scale is comprised of nine values, namely: a sense of belonging, excitement, warm relationships with others, self-fulfilment, being well respected, fun and enjoyment, security, self-respect, and a sense of accomplishment. Past research (Kahle, 1983, Homer and Kahle, 1988) demonstrates that the nine LOV values can be reduced to a smaller number of underlying dimensions related to locus of control. More specifically, Homer and Kahle (1988) identified the subsets of external values (sense of belonging, being well respected, and security) along with the individual values (selffulfilment, excitement, sense of accomplishment, and self-respect), and the interpersonal values (fun and enjoyment and warm relationship with others). This study utilized the described mapping of LOV values onto underlying dimensions to assess the influence of external values on a respondent's satisfaction with Hoopfest. Externally oriented people should prioritize developing and sustaining social relationships over other personal goals. Due to the highly social and communal nature of amateur team sports, and basketball in particular, Hoopfest provides an opportunity for externally oriented people to fulfil social value needs. They will likely be more motivated by the opportunities for social interaction provided by attending or participating in Hoopfest. Support for this conjecture can also be found in Green (2001) who proposes that sport events can be augmented if they are designed to appeal to the values of the sport subculture to which the event is targeted. As long as the sport event fulfils the values that are central to the targeted sport subculture, a positive relationship between this set of values and 
satisfaction with the sport event should be present. The prior discussion naturally leads to the formulation of the following two hypotheses:

H1: External values in the List of Values scale affect satisfaction with the Hoopfest community sport event.

H2: The importance of the Hoopfest community sport event to the Spokane community is related to satisfaction with Hoopfest.

Higher levels of consumer retention should result when attendees associate desired social benefits with a community sport event. These satisfied individuals will also spread positive word of mouth making it much easier and less expensive to attract additional attendees as well as sponsors. As a result, attendee satisfaction should serve as a leading indicator of future community sport event performance. The viability of any community sport event will depend not only on high average levels of attendee satisfaction but also the consistency with which each attendee has a satisfactory experience. The focus of event improvements should not rely on just increasing mean satisfaction levels but should also strive to reduce the variance associated with mean satisfaction scores (Aquilano, Chase \& Davis 1995). Every community sport manager must be concerned with both maintaining high mean satisfaction and ensuring that individual experiences are consistent.

An attendee who has one bad experience is less likely to return in the future, regardless of how many times they may have participated in the past, and are a potential source of negative word of mouth. Therefore, the goal of every community sport manager should be to achieve high levels of event satisfaction with little variability in attendee experience. Attendee satisfaction which is already high can be improved upon by reducing satisfaction variance. Even a small variance in attendee satisfaction with the social benefits provided by a community sport event could become the focus of continuous improvement efforts. A variance in event satisfaction may negatively impact an organization's future revenue stream as well as community support. The level and consistency of attendee satisfaction are consequently forward looking diagnostics that can be useful as a benchmarking tool for improving community sport events. The intention to participate in future events will be higher among those who are satisfied with an event. This view is advanced in our third hypothesis.

H3:Attendee intention to participate in a future Hoopfest is directly related to community sport event satisfaction.

Improvement in a community sport event can be defined by how well and/or consistently it meets the social value expectations of community sport attendees. Assessing the social benefits that attendees associate with a sport event, however, is not a standardized process. The difficulty in assessing social values is, in part, determining what social value questions are important and how those social values are related to attendee satisfaction. Satisfaction 
surveys are a common process improvement tool which has been used by community sport event practitioners. Seldom, however, have such surveys explicitly linked how well a community sport event meets or exceeds attendee social benefit expectations. Efforts to improve a community sport event should not rely on conjecture regarding important social values rather than understanding how a community sports event delivers on expressed (or implied) promises of social benefit.

\section{Method}

We used satisfaction surveys to measure the social benefits attendees associated with Hoopfest. Similar survey methodologies have been noted as an important way sport marketers and managers can better serve the needs of the community and design superior events (Rohm, Milne \& McDonald 2006). A disproportionate interval random sample was taken of Hoopfest participants, spectators, and volunteers. Forty-five areas were selected from a numbered geographic grid of the event site using a random number table. A half hour interview period, for each of the 45 areas, was chosen using the same procedure. Three teams of interviewers approached up to 2 volunteers, 4 players, and 5 spectators at each of the specified locations and times. Each team was composed of three members. Two floating supervisors ensured the sampling plan was followed as well as all interviews were conducted in the prescribed manner.

A survey team went to the northwest corner of each selected area at the time specified to administer pen and paper surveys to the closest 5 spectators. Once the game was over, the closest basketball team to the randomly selected starting point was asked to complete the survey (each team was limited to no more than 4 players). The court monitor and volunteer score keeper, if there was one of the latter, were also asked to complete the questionnaire. Up to 11 pen and paper surveys could therefore be completed at each sampled area. 418 out of the 470 people approached completed the survey.

Eleven surveys were eliminated from the analysis for failing to follow instructions. Another 14 respondents did not belong to either a player, a spectator, or a volunteer group; they were vendors or downtown residents and were subsequently excluded from the analysis. This resulted in a sample size of 393 usable surveys with a response rate of $83.6 \%$.

\section{Results}

Data analysis was conducted using $\mathrm{R}$ statistical programming language ( $\mathrm{R}$ Core Team, 2013). Of the 393 usable surveys, 204 (51.9\%) were completed by people who self-identified as players and $189(48.1 \%)$ by spectators or volunteers (some of the spectators interviewed were players watching other games). $48 \%$ of the respondents were women. (The percentages of women who 
were players, spectators, and volunteers were 32.31, 75.41, and 43.33, respectively.) The mean age of a respondent was 32.25 (st. dev.=16.36), and ranged in age from 8 to 89 years old. (The mean ages of players, spectators, and volunteers were 25.86, 38.48, and 39.73, respectively.) Data also suggest high levels of loyalty to Hoopfest. The mean number of times respondents had attended Hoopfest was 6.51 (st. dev. = 5.97), with the range extending from 1 time to 24 times.

Social values were measured using the List of Values (Kahle, 1983) 9point scale where 1 was very unimportant and 9 was very important. All values were deemed highly important by the respondents. The mean ratings for each value in the LOV scale are provided in Table 1 below.

Table 1. List of Values Ratings

\begin{tabular}{|lcc|}
\hline & Mean & Std.Devn \\
\hline Sense of belonging & 7.65 & 1.65 \\
Excitement & 7.89 & 1.39 \\
Warm relationships & 7.92 & 1.42 \\
Self-fulfillment & 7.93 & 1.44 \\
Being well respected & 7.87 & 1.66 \\
Fun and enjoyment & 8.38 & 1.07 \\
Security & 7.92 & 1.58 \\
Self-respect & 8.28 & 1.23 \\
Sense of accomplishment & 8.29 & 1.12 \\
\hline
\end{tabular}

\section{Hypothesis 1}

We hypothesized that external (social affiliation) values would affect satisfaction with Hoopfest. Evidence in favor of this hypothesis would be important for organizers of community sporting events for several reasons. First, satisfaction is a critical forward looking performance metric. Satisfied customers are more likely to be loyal consumers, which also makes recruiting new attendees less expensive through referrals and positive word of mouth. Second, it can help act as a competitive barrier by reducing the incentive to substitute other recreation oriented products. We used OLS regression to test the effect of different factors that affected attendee satisfaction. Table 2 summarizes a variety of behavioral, demographic and personal characteristics that could have had an influence on attendee satisfaction.

Overall, respondents were very satisfied with their Hoopfest experience: mean of 5.61 (st. dev. $=.67$ ) measured on a 6-point scale ranging from $1=v e r y$ dissatisfied to $6=v e r y$ satisfied. The regression of LOV scale ratings and other independent variables (primary reason for attending, number of pervious times attending Hoopfest, Caught-up feelings, Understand other feelings, Gender, and Age) on Hoopfest satisfaction ratings was significant $(F(17,311)=2.38, p=.002)$. 
Table 2. Variables Affecting Attendee Satisfaction

\begin{tabular}{|lcccc|}
\multicolumn{1}{l}{ (Intercept) } & Estimate & Std. Error & $\mathrm{t}$ value & $\operatorname{Pr}(>|\mathrm{t}|)$ \\
Primary.ReasonWatch & 3.00 & 0.57 & 5.28 & $0.00^{*}$ \\
Primary.ReasonVolunteer & -0.03 & 0.09 & -0.36 & 0.72 \\
Total.Times & -0.11 & 0.11 & -0.99 & 0.32 \\
Importance to Spokane & 0.00 & 0.01 & 0.54 & 0.59 \\
Belonging & 0.24 & 0.08 & 2.82 & $0.01^{*}$ \\
Excitement & 0.11 & 0.03 & 3.67 & $0.00^{*}$ \\
Warm Relationships & 0.01 & 0.03 & 0.26 & 0.80 \\
Self-fulfillment & -0.02 & 0.03 & -0.53 & 0.60 \\
Being Respected & -0.01 & 0.04 & -0.23 & 0.82 \\
Fun Enjoyment & -0.08 & 0.03 & -2.51 & $0.01^{*}$ \\
Security & 0.01 & 0.05 & 0.26 & 0.79 \\
Self-respect & -0.01 & 0.03 & -0.42 & 0.67 \\
Accomplishment & 0.07 & 0.04 & 1.61 & 0.11 \\
Caughtup Feelings & 0.04 & 0.04 & 0.97 & 0.33 \\
Understand Other Feelings & 0.00 & 0.03 & -0.07 & 0.94 \\
Gender-Male & 0.03 & 0.04 & 0.69 & 0.49 \\
Age & -0.04 & 0.08 & -0.51 & 0.61 \\
\hline
\end{tabular}

* Estimates are significant with a p-value of less than .01 .

Satisfaction was significantly and positively affected by attendees' sense of belonging $(t=3.67 . p=.00)$ and was negatively related to being respected ( $t=-$ $2.51, p=.01)$. The external value of security did not have a significant effect on satisfaction. There is little doubt that this community-based amateur sport event is uniquely well positioned to fulfil the attendees' sense of belonging to the sport subculture (basketball) community as well as to the greater Spokane community. The value of security was neither positively nor negatively related to Hoopfest satisfaction, perhaps because attending this event neither challenges nor affirms an attendee's sense of security. The negative relationship between the external value of being respected and satisfaction is not surprising. Participants have no expectation that they will always be respected by the other members of this sport community. The need to always feel the respect and admiration of others is hardly compatible with an amateur basketball tournament. Almost every participant will fail to affirm his or her basketball prowess and, as a consequence, experience a blow to one's selfesteem.

Please note that we did not find any discernable pattern between the residuals and fitted values of satisfaction, suggesting that a homoscedastic linear model was present. A studentized Breusch-Pagan test also indicated the presence of homoscedasticity $(\mathrm{BP}=15.09, \mathrm{df}=17, p=.59)$.

\section{Hypothesis 2}

We also hypothesized that the perceived importance of Hoopfest to the Spokane community would positively affect satisfaction with the community sport event. Empirical evidence linking event importance ratings with 
satisfaction would provide additional support for the theoretical viewpoint that proposes community sport events can be central in building and sustaining a sense of community identity (e.g., Ingham \& McDonald, 2003; Schulenkorf, 2009; Verweel \& Anthonissen, 2006). The observed relationship between the importance of the event to Spokane and Hoopfest satisfaction was indeed significant $(t=2.82, p=.01)$ and supports such an interpretation.

We visualized the terms provided in response to two open-ended questions to provide additional evidence in favor of this interpretation. The first question asked why respondents felt Hoopfest was important to the Spokane community and the second question asked what they liked about Hoopfest. Figure 1 is a word cloud (Fellows, 2013) of these terms. In it, the size of a term is proportionate to the frequency with which it was mentioned. (Larger terms were used more frequently than smaller terms.) "Community," "together," and "people" were among the highest-frequency terms in the open-ended answers to the question about the reasons for Hoopfest-importance. Communitycentered and social interaction-centered terms "playing," "community," "family," "friends," "fun" were among the most frequently named reasons for liking Hoopfest. Responses to the open-ended questions therefore provide qualitative support to our hypothesis that social affinity is important for respondents.

Figure 1. Word Clouds of Open-ended Terms Importance of Hoopfest. What is liked about Hoopfest
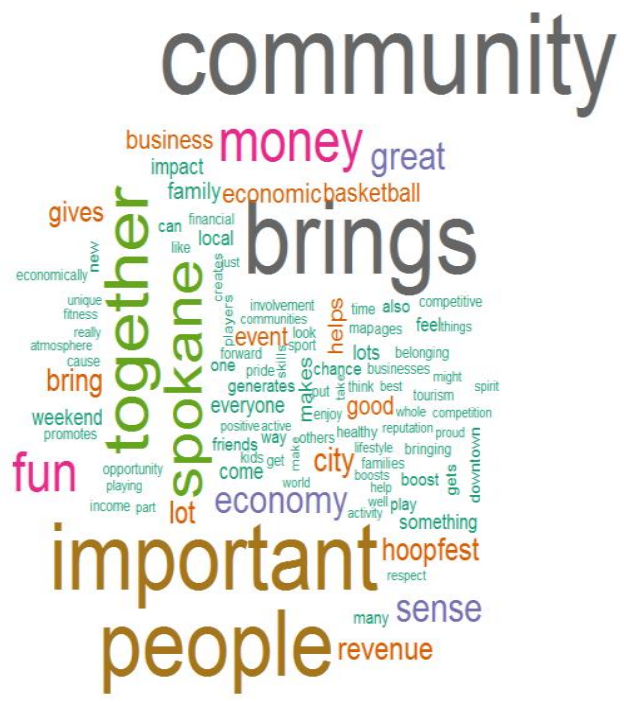

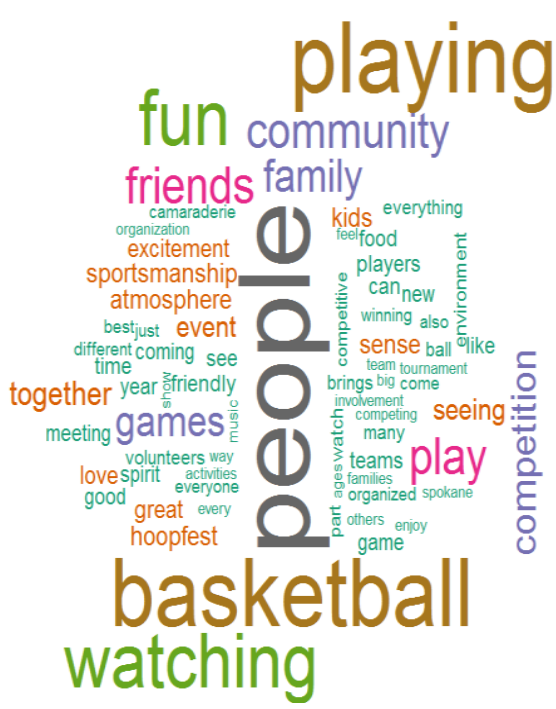

Hypotheses 3

Our third hypothesis examines whether attendee intentions to participate in future Hoopfests are directly related to community sport event satisfaction. 260 of $393(66.2 \%)$ respondents planned to "definitely attend", while 91 of them $(23.2 \%)$ thought that they would "probably attend" Hoopfest next year. On a 5point scale, where 1 was definitely will not attend and 5 was definitely will attend, the mean intention to attend Hoopfest next year was very high 
$(\mathrm{M}=4.53$, st. dev. $=.75)$. Table 3 reveals the relationship been the intention to attend Hoopfest in the future and mean satisfaction scores.

Table 3. Likelihood of Attending in Future and Satisfaction

Likelihood of attending Number of People Percent Mean Satisfaction

\begin{tabular}{|lccc|}
\hline Definitely will not & 2 & 0.51 & 6 \\
Probably will not & 5 & 1.27 & 4.2 \\
May or may not & 35 & 8.91 & 5 \\
Probably will & 91 & 23.16 & 5.53 \\
Definitely will & 260 & 66.16 & 5.75 \\
\hline
\end{tabular}

Recall that event satisfaction was measured on a 6 point scale ranging from being very dissatisfied to very satisfied. Therefore, even the two participants who indicated they would definitely not attend next year were very satisfied with the event. This suggests that there may have been uncontrollable factors guiding their certainty of not attending the event the following year. Besides this group of two people, higher levels of satisfaction were consistently associated with a higher likelihood of attending the event in the future. In sum, we found considerable evidence which supports our third hypothesis that the likelihood of attending Hoopfest in the future is greater for those who were more satisfied with the event. Respondents' satisfaction with Hoopfest was significantly correlated with their intention to participate in another Hoopfest $(t=.347, p<.001)$.

Figure 2. Likelihood of Attending in Future, Number of People, and Satisfaction

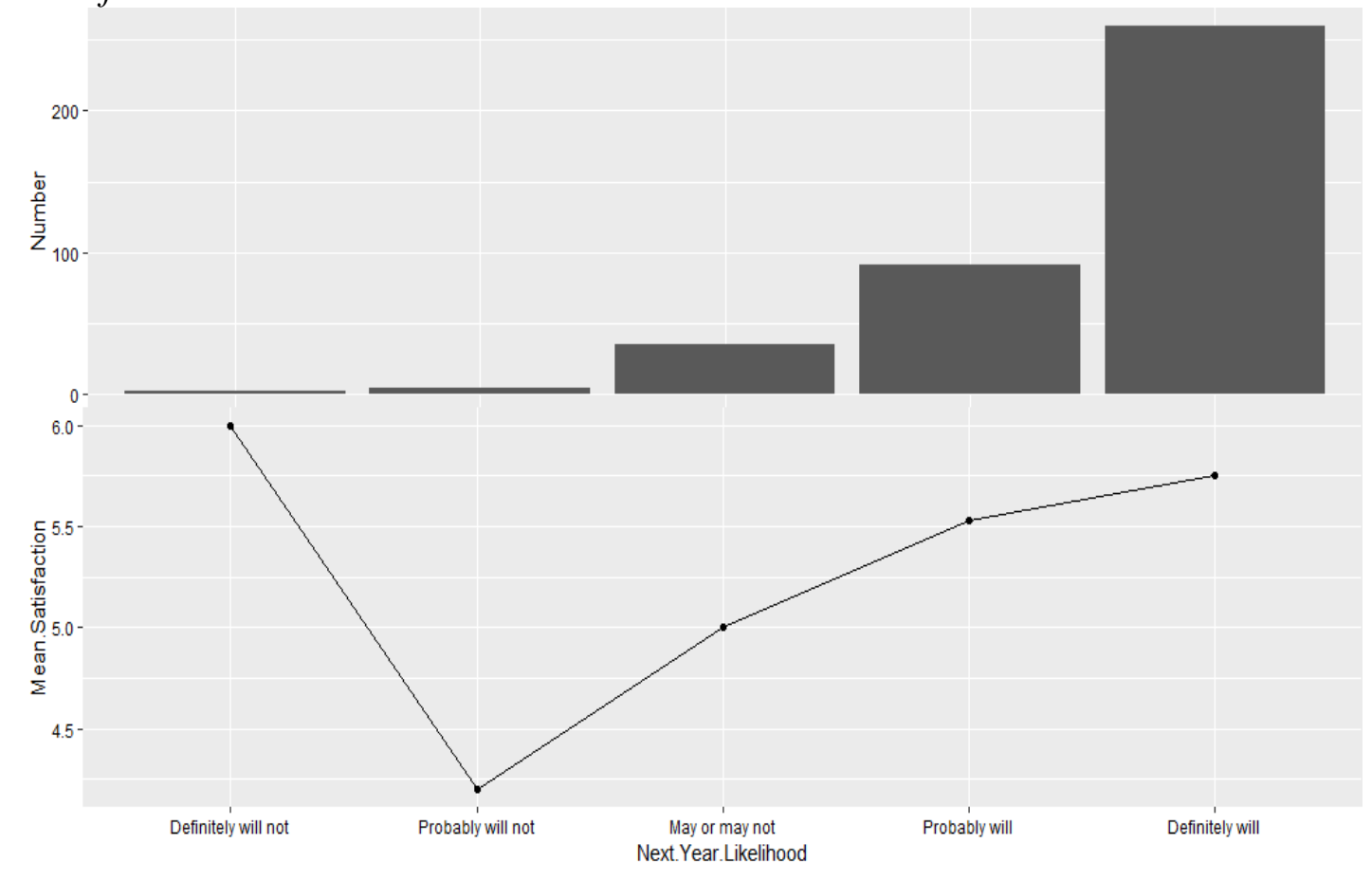


Table 3 provides a tabulation of how mean satisfaction levels varied across participants and relates to our question on the likelihood of people attending Hoopfest the following year (Wickham, 2009). Note how, except for the two individuals discussed previously, mean satisfaction levels are not only linearly related to future intentions but also exhibit diminishing returns.

\section{Conclusion and Suggestions for Future Research}

Our research provides empirical support to the notion that communitybased sporting events are a means for fulfilling social values and may be important to specific sport subcultures (Green, 2001; Kurpis \& Bozman, 2011). An a priori identification of social values that are central to the identity of basketball players and spectators led us to propose that external (social affiliation) values from the LOV scale (Kahle, 1983) were likely to satisfy this need. A word cloud analysis of respondents' open-ended answers to questions about the importance of Hoopfest and the aspects of the sport festival which they particularly liked also support this perspective. The community and social affiliation-centered aspects of Hoopfest were most frequently referred to by survey participants and indicate the centrality of these components to their sport event experience.

Community sport events provide many opportunities for participants and spectators to fulfil a broad variety of sport-related values. Our quantitative findings demonstrate that when values central to an attendee's identity are fulfilled, he or she is more likely to experience satisfaction with the sport event. Indeed, two of the three values constituting the external dimension of the LOV scale were significant predictors of respondent satisfaction with Hoopfest. The perceived importance of Hoopfest to the Spokane community was also a significant predictor of an attendee's satisfaction with the event. This latter finding suggests that in respondents' minds, the communal aspect of Hoopfest is an integral part of the event's attraction. Satisfaction with Hoopfest was also significantly related to respondent intentions to attend or participate in the next installment of the sport festival.

Our findings could suffer from certain limitations. For example, there may be unobserved variables that could result in an omitted variable bias in our observed relationships. Although we attempted to identify behavioral, personal, and demographic characteristics of respondents that we believed were important and relevant to our analyses, it is difficult for us to completely rule out unobserved heterogeneity in our sample.

Overall, our results suggest community sport organizers should be aware of the social affiliation and communal aspects of a community sport event and include community-focused benefits in an event in order to fulfil social values and increase satisfaction among event attendees. Determining which social values are most central to a particular sport subculture and then designing and promoting sport events in a way that ensures fulfilling those values could provide viable avenues for enhancing the appeal of any community sport event. 
Achieving higher and more consistent levels of attendee satisfaction with a community sport event may be particularly important as a means of continuous improvement because it leads to behavioral loyalty and perpetuates the positive social legacy of any sport event.

This study contributes to sport management and marketing research by empirically establishing a link between a subset of external social values from the LOV scale, attendee satisfaction, and behavioral intentions with regard to a community sporting event. It also begins an exploration which suggests it may be possible to identify a set of social values that are central to a particular sport subculture and consequently design community sport events which better satisfy different types of participants. For example, a community sport event like Hoopfest may approach capacity constraints on the number of basketball players but still desire growth in the number of spectators. Knowledge of the unique social benefits spectators desire to fulfil could allow Hoopfest management to achieve greater spectator attendance goals without sacrificing player satisfaction.

Future research could endeavor to develop an instrument and/or methodology that better identifies and distinguishes important sport related social benefits. The LOV scale was not designed for this purpose. Equipping sport event organizers with a comprehensive list of desired outcomes would permit them to differentiate between those most important to an audience(s) and design an event which better satisfies participants and also serves as a benchmark for event improvement. Satisfied event attendees should make it much easier to elicit support from other community residents and business leaders. Sport events designed and promoted with community social benefits in mind will result in higher levels of satisfaction and behavioral loyalty as well as help ensure the longer term sustainability of any community sport.

\section{References}

Chalip, L. (2006). Towards social leverage of sport events. Journal of Sport Tourism, 11(2), 109-127.

Chalip, L., Lin, Y-C., Green, B. C., \&Dixon, M. A. (2013). The essential role that sense of community plays in consumption of a shared service: Lessons from youth sport. In J. Sundbo \& F. Sørensen (Eds.), Handbook on the experience economy (pp. 325-338). Cheltenham, UK: Edward Elgar.

Chalip, L. \& McGuirty, J. (2004). Bundling sport events with the host destination. Journal of Sport \& Tourism, 9(3), 267-282.

Costa, C., Chalip, L., Green, B. C., \& Simes, C. (2006). Reconsidering the role of training in event volunteers' satisfaction. Sport Management Review, 9, 165-182.

Fellows, I. (2013). wordcloud: Word Clouds (R package version 2.4) . Available from http://CRAN.R-project.org/package=wordcloud

Green, B.C. (2001). Leveraging subculture and identity to promote sport events. Sport Management Review, 4, 1-19.

Homer, P.M. \& Kahle, L.R. (1988). A structural equation analysis of the valueattitude-behavior hierarchy. Journal of Personality and Social Psychology, 54 (3), 638-646. 
Hoye, R., Nicholson, M., \& Brown, K. (2015). Involvement in sport and social connectedness. International Review For The Sociology Of Sport, 50(1), 3-21. doi:10.1177/1012690212466076

Ingham, A. G. \& McDonald, G. (2003). Sport and Community/Communitas. In R.C.

Wilcox, D.L. Andrews, R. Pitter \& R.L. Irwin (Eds.), Sport Dystopias: The Making and Meanings of Urban Sport Cultures (pp. 17-33) . Albany, NY: State University of New York Press.

Kahle, L. R. (1983). Social Values and Social Change: Adaptation to Life in America. New York, NY: Praeger.

Kahle, L.R., Duncan, M., Dalakas, V., \& Aiken, D. (2001). The social values of fans for men's versus women's university basketball. Sport Marketing Quarterly, $10(2), 156-162$.

Keller, K.L. (1993). Conceptualizing, measuring, and managing customer-based brand equity. Journal of Marketing, 57(1), 1-22.

Kim, M., Chelladurai, P., \& Trail, G. T. (2007). A model of volunteer retention in youth sport. Journal of Sport Management, 21(2), 151-171.

Kurpis, L., Bozman C.S., \& Kahle L.R. (2010). Distinguishing between amateur sport participants and spectators: The list of values approach. International Journal of Sport Management and Marketing, (3/4), 190-201.

Lawson, H. A. (2005). Empowering people, facilitating community development, and contributing to sustainable development: The social work of sport, exercise, and physical education programs. Sport, Education \& Society, 10(1), 135-160.

Pederson, P.M., Parks, J., \& Quarterman, J. (2011). Contemporary Sport Management, 5th ed., Human Kinetics, p. 192.

Park, C.W., MacInnis, D.J., Priester, J., Eisingerich, A.B., \& Lacobucci, D. (2010). Brand attachment and brand attitude strength: Conceptual and empirical differentiation of two critical brand equity drivers. Journal of Marketing, 74(6), $1-17$.

Preuss, H. (2007). The conceptualization and measurement of mega sport event legacies. Journal of Sport Tourism, 12(3/4), 207-227.

$\mathrm{R}$ Core Team (2013). $R$ : A language and environment for statistical computing. Vienna, Austria: R Foundation for Statistical Computing. Retrieved from http://www.R-project.org/

Rohm, A.J., Milne G.R., \& McDonald, M.A. (2006). A mixed-method approach for developing market segmentation typologies in the sports industry. Sport Marketing Quarterly, 15(1) , 29-39.

Rueda-Cantuche, J.M. \& Ramirez-Hurtado, J.M. (2007). A simple-to-use procedure to evaluate the social and economic impacts of sporting events on local communities. International Journal of Sport Management and Marketing, (5/6) , 510-525.

Schulenkorf, N. (2009). An ex ante framework for the strategic study of social utility of sport events. Tourism and Hospitality Research, 9(2), 120-131.

Umberson, D., Crosnoe, R., \& Reczek, C. (2010). Social relationships and health behavior across the life course. Annual Review Of Sociology, 36(1), 139-157.

U.S. Census of Population. (2010). Retrieved from http://www.census.gov/2010 census/popmap/ipmtext.php?fl=53:53063, April 21, 2014.

Verweel, P. \& Anthonissen, A. (2006). Ethnic diversity in organized sport: Development of social capital by Dutch immigrants. The Cyprus Journal of Sciences, (4), $109-128$.

Wickham, H. (2009). ggplot2: Elegant Graphics for Data Analysis. Springer: New York. 
Xing, X., Chalip, L., \& Green, B. C. (2014). Marketing a social experience: How celebration of subculture leads to social spending during a sport event. Sport Marketing Quarterly, 23(3), 138-147. 